\title{
Etika Bugis dalam Novel Sajak Rindu Lontara Cinta dari Sidenreng dan Kontribusinya Terhadap Pendidikan Karakter di Sekolah
}

\author{
Dedi Ardiansyah*, Munirah, Andi Agussajim Aj \\ Program Pascasarjana Universitas Negeri Makassar \\ *Corresponding Author. Email: dediardiansyah138@gmail.com
}

\begin{abstract}
This study aims to describe the form of Bugis ethics and its contribution to character education in schools in the novel Sajak Rindu Lontara Cinta from Sidenreng. This study used a descriptive method with a qualitative approach. This study used a literary anthropological approach with local wisdom theories. The data were obtained through literature study. Data analysis techniques used data reduction, data presentation, and drawing conclusions. The data of this study were analyzed by describing the forms of Bugis ethics, namely sipakatau, sipakalebbi, and sikapale. The results of the analysis of the novel Sajak Rindu Lontara Cinta dari Sidenreng by S. Gegge Mappangewa found that sipakatau, sipakalebbi, and sikapale contributed to character education in schools as the first step to form good character for students.
\end{abstract}

\begin{abstract}
Abstrak: Penelitian ini bertujuan untuk mendeskripsikan bentuk etika Bugis dan kontribusinya terhadap pendidikan karakter di sekolah dalam novel Sajak Rindu Lontara Cinta dari Sidenreng. Penelitian ini menggunakan metode deskriptif dengan pendekatan kualitatif. Penelitian ini menggunakan pendekatan antropologi sastra dengan teori-teori kearifan lokal. Data diperoleh melalui metode strudi pustaka. Teknik analisis data yang digunakan yakni reduksi data, penyajian data, dan penarikan simpulan. Data dalam penelitian ini dianalisis dengan mendeskripsikan bentuk etika Bugis yaitu sipakatau, sipakalebbi,dan sipakainge. Hasil analisis novel Sajak Rindu Lontara Cinta dari Sidenreng karya S. Gegge Mappangewa menemukan yaitu sipakatau, sipakalebbi, dan sipakainge, ini kemudian dikontribusikan terhadap pendidikan karakter disekolah sebagai langkah awal untuk membentuk karakter yang baik kepada peserta didik.
\end{abstract}

\section{Article History}

Received: 02-05-2021

Revised: 21-06-2021

Accepted: 07-08-2021

Published: 07-09-2021

\section{Key Words:}

Bugis Ethics, Character

Education, Local Wisdom.

\section{Sejarah Artikel}

Diterima: 02-05-2021

Direvisi: 21-06-2021

Disetujui: 07-08-2021

Diterbitkan: 07-09-2021

\section{Kata Kunci:}

Etika Bugis,

Pendidikan Karakter,

Kearifan Lokal.

How to Cite: Ardiansyah, D., Munirah, M., \& Agussajim Aj, A. (2021). Etika Bugis dalam Novel Sajak Rindu Lontara Cinta dari Sidenreng dan Kontribusinya Terhadap Pendidikan Karakter di Sekolah. Jurnal Kependidikan: Jurnal Hasil Penelitian dan Kajian Kepustakaan di Bidang Pendidikan, Pengajaran dan Pembelajaran, 7(3), 589-595. doi:https://doi.org/10.33394/jk.v7i3.3825

\section{Pendahuluan}

Antropologi sastra adalah analisis terhadap karya sastra yang didalamnya terkandung unsur-unsur antropologi. Analisis antropologi sastra adalah usaha untuk memberikan identitas terhadap karya sastra dengan menganggapnya sebagai aspek tertentu yaitu hubungannya dengan ciri-ciri kebudayaan. Hubungan ini jelas karena karya sastra menduduki posisi dominan, sebaliknya aspek-aspek antropologi sebagai pelengkap (Ratna, 2011).

Keterkaitan antara kebudayaan dan karya sastra merupakan fenomena di masyarakat secara berkelompok yang membentuk sebuah kebudayaan. Aspek budaya tentunya berkaitan dengan ilmu pengetahuan, kepercayaan, kesenian, moral, hukum, dan adat-istiadat. Sehubungan dengan hal ini, menurut Endraswara (2013) yang menjadi bahan penelitian antropologi sastra adalah sikap dan perilaku manusia lewat fakta-fakta sastra dan budaya. Antropologi sastra berupaya untuk meneliti sikap dan perilaku yang muncul dalam sebuah 
karya sastra. Manusia sering bersikap dengan tata krama yang memuat tata susila dalam bahas interaksi budaya satu sana lain yang penuh simbol.

Ketika menggunakan kajian antropologi sastra sebagai payung penelitian berarti dibutuhkan sebuah objek yaitu karya sastra khususnya novel. Novel merupakan bagian dari prosa fiksi. Novel merupakan salah satu hal yang bisa dijadikan sebagai tempat untuk menceritakan segala aspek kehidupan manusia melalui alur cerita yang membahas tentang sebuah kebudayaan. Novel menceritan kisah yang lebih bebas, detail, rinci, dan berisi masalah yang lebih kompleks (Nurgiyantoro, 2015).

Novel yang baik tidak hanya berfungsi sebagai hiburan yang menyenangkan tetapi memberikan pesan positif bagi para pembacanya. Salah satu novel yang menarik untuk dibahas yaitu novel yang berjudul Sajak Rindu Lontara Cinta dari Sidenreng karya S. Gegge Mappangewa (2016). Novel ini menceritakan kehidupan manusia yang didalamnya penuh dengan etika yang mereka pahami dan juga dijadikan sebagai falsafat hidup masyarakat bugis. Novel ini juga banyak membahas tentang kehidupan masa lampau mayarakat Bugis baik itu kepercayaan, adat istiadat, hukum, dan tentunya etika itu sendiri. Novel ini adalah prasasti budaya Bugis. Relief latarnya terlihat jelas di antara alunya yang mengalir dan menghanyutkan serta seakan-akan pembaca kembali ke perkampungan Bugis pulahan tahun silam.

Etika masyarakat yang diceritakan dalam sebuah novel merupakan suatu kebiasan tata krama dalam berprilaku sehari-hari dalam lingkungan masyarakat. Etika tersebut dijadikan sebagai falsafah hidup dan merupakan simbol jati diri masyarakat Bugis dalam bersikap dan berinteraksi (Fatmawati, 2015), artinya etika ini telah diterapkan dan ditanamkan dalam diri masyarakat Bugis terdahulu. Secara internal yakni suatu perwujudan sikap yang sadar atau tidak, langsung atau tidak, telah menjadi undang-undang tak tertulis dalam apresiasi sikap dalam masyarakat suku Bugis.

Pentingnya etika dalam hidup masyarakat agar mereka saling mengenal, saling menghargai, saling pengertian dan sebagainya. Seharusnya pada era sekarang ini moral maupun etika masyarakat dibentuk secara kuat dengan aturan adat dan nilai-nilai etika agar tidak terjadi penyimpangan dan konflik permasalahan etika pada masyarakat. Saat ini telah terjadi pergeseran nilai budaya yang tidak lagi konsisten dengan konteks dasar etika (Safriadi, 2020).

Karya sastra memiliki nilai pendidikan karakter yang dapat digunakan untuk memberikan pembelajaran kepada para siswa dan masyarakat (Syarif, 2021). Sebuah karya sastra khususnya novel yang didalamnya menceritakan tentang etika bisa dijadikan sebagai bahan untuk pendidikan karakter di sekolah. Pendidikan karakter merupakan kegiatan untuk membentuk karakter dalam diri siswa untuk menjadi pribadi yang baik (Mulyasa, 2011). Sekarang ini usia remaja rawan terhadap pengaruh negatif karena masa ini merupakan masa puncak kelabilan. Masa ini sangat berbahaya jika terpengaruh orang dewasa yang tidak bertanggung jawab, maka penting dilakukan penanganan melalui pendidikan karakter

Pendidikan karakter adalah pendidikan budi pekerti, yaitu melibatkan aspek pengetahuan, perasaan, dan tindakan. Pendidikan karakter diterapkan secara sistematis dan berkelanjutan. Seoarang anak akan menjadi cerdas emosinya dan ini merupakan bekal untuk mempersiapkan anak menyongsong masa depan karena seorang anak akan lebih mudah dan berhasil menghadapi segala macam tantangan kehidupan termasuk tantangan untuk berhasil secara akademis. Pendidikan karakter sangat penting untuk diterapkan kepada siswa, ketika seseorang tidak memiliki etika yang baik, ia akan semena-mena kepada siapa saja termasuk orang tua, guru, sahabat, dan orang-orang disekitarnya (Zulhan, 2011). Beragam fenomena 
masa kini menantang peserta didik memiliki kepakaan dan kesadaran terhadap derita dan budaya bangsa hingga nilai kemanusiaan dapat terbentuk (Fatimah, 2021).

Fenomena-fenomana yang terjadi disekolah akhir-akhir ini yang melibatkan siswa dan guru, kasus yang terjadi di SMP 20 Bulukumba, siswa berkelahi dengan guru akibat pnses siswa tersebut disita (Detik.com, 2019).Kasus serupa terjadi di SMA Negeri 3 Wajo, guru yang telah mengajar lebih 10 tahun tersebut dipolisikan oleh siswanya karena mencubut siswa yang tidak mengikuti kelas mata pelajaran kewirausahaan. Kejadian-kejadian tersebut hanya sedikit dari banyaknya kasus seperti itu. Semuanya sudah lebih dari cukup untuk menggambarkan betapa buruknya etika siswa saat ini.

Teori yang dapat digunakan dalam kajian antropologi sastra yaitu teori-teori kearifan lokal. kearifan lokal secara konseptual merupakan kebijaksanaan manusia yang bersandar pada filosofi nilai-nilai, etika, cara-cara, dan perilaku yang melembaga secara tradisional. Selain sistem norma dalam kebudayaan lokal juga terkandung pengetahuan lokal, pengetahuan tradisional, yaitu berbagai konsep, bahlan teori yang sudah digunakan oleh nenek moyang dalam rangka menopang keberlangsungan kehidupannya (Ratna, 2011).

kearifan lokal yang menjadi acuan masyarakat meliputi seluruh aspek kehidupan, berupa tata aturan yang menyangkut hubungan antar sesama manusia, misalnya aturan perkawinan, tata krama dalam kehidupan sehari-hari, tata aturan menyangkit hubungan manusia dengan alam, binatang, tumbuh-tumbuhan yang lebih bertujuan pada upaya konservasi alam, dan tata aturan yang menyangkut hubungan manusia dengan yang gaib, misalnya Tuhan dan roh-roh gaib. Kearifan lokal juga dapat berupa adat istiadat, institusi, kata-kata bijak, dan pepatah (Marsono, 2007).

Studi antropologi sastra adalah studi yang menganalisis karya sastra yang didalamnya memiliki ciri-ciri antropologi (Ratna, 2011). Studi antropologi sastra telah dilakukan oleh Dia Ayuningtyas (2015) yang mengungkapkan nilai budaya pada novel Bunga Kedaton karya Wahyu H.R dan implementasinya dalam pembelajaran sastra. Hasil yang ditemukan yaitu nilai budaya dalam hubungan manusia dengan tuhan, nilai budaya dalam hubungan manusia dengan masyarakat, nilai budaya dalam hubungan manusia dengan orang lain, nilai budaya dalam hubungan manusia dengan diri sendiri, nilai budaya dalam hubungan manusia dengan alam dan hasik penelitian ini dapat diimplementasikan sebagai bahan ajar sastra di SMA karena memuat unsur intrinsik dan ekstrinsik yang dapat digunakan dalam pembelajaran sastra.

Selanjutnya, yang dilakukan oleh Nindya Riski Dianita (2018) tentang sikap hidup siri na pesse masyarakat Bugis dalam novel Calabai perempuan dalam tubuh lelaki karya Pepi Al-bayqumie. Hasil penelitian ini kemudian menemukan sikap alempureng masyarakat Bugis, sikap hidup amaccangen masyarakat Bugis, sikap hidup awaraning masyarakat Bugis, sikap hidup agettengeng masyarakat Bugis, sikap hidup rese na tinulu masyarakat Bugis, dan sikap mappasitinaja masyarakat Bugis.

Berdasarkan penelitian terdahulu dapat diketahui bahwa belum ada yang meneliti mengenai etika Bugis yaitu sipakatau, sipakalebbi, dan sipakainge dalam novel Sajak Rindu Lontara Cinta dari Sidenreng yang kemudian dikontribusikan terhadap pendidikan karakter di sekolah menggunakan kajian antropologi sastra. Sehingga penelitian ini penting untuk dilakukan mengingat karya sastra dapat digunakan sebagai penghubung untuk membentuk karakter melalui novel kepada para pembaca khususnya peserta didik. 


\section{Metode Penelitian}

Metode penelitian ini menggunakan penelitian kualitatif yang bersifat deskriptif. Fokus penelitian ini adalah mengkaji etika Bugis dalam novel Sajak Rindu Lontara Cinta dari Sidenreng karya S. Gegge Mappangewa dan kontribusinya terhadap pendidikan karakter di sekolah menggunakan kajian antropologi sastra dengan teori-teori kearifan lokal. Data dalam penelitian ini berupa kata, frasa, klausa, dan kalimat dalam novel Sajak Rindu Lontara Cinta dari Sidenreng yang memuat etika Bugis menggunakan metode dokumentasi dengan teknik baca dan catat. Teknik analisis data menggunakan teknik analisis Miles dan Huberman (2009) yang terdiri atas tiga tahap yakni reduksi data, penyajian data, dan penarikan simpulan.

\section{Hasil Penelitian dan Pembahasan}

Hasil analisis dalam penelitian ini terdapat dua bagian yaitu (1) bentuk etika Bugis dalam novel Sajak Rindu Lontara Cinta dari Sidenreng karya S. Gegge Mappangewa. (2) kontribusi analisis novel Sajak Rindu Lontara Cinta dari Sidenreng karya S. Gegge Mappangewa terhadap pendidikan karakter di sekolah.

\section{1) Bentuk etika Bugis dalam novel Sajak Rindu Lontara Cinta dari Sidenreng}

Etika atau akhlak terkait dengan keyakinan, sikap, aktivitas atau perasaan atas sesuatu akan menentukan tindakan dan perilaku sehari-hari (Sagala, 2013). Dari hasil pembacaan terhadap novel Sajak Rindu Lontara Cinta dari Sidenreng ditemukan bahwa bentuk etika Bugis yakni Sipakatau, Sipakalebbi, dan Sipakainge.

\section{a) Sipakatau}

Sipakatau (saling memanusiakan) merupakan nilai dasar berdimensi sosial-horizontal dan vertikal yang berarti saling memanusiakan atau saling memperlakukan sebagai manusia. Di dalam interaksi sosial, prinsip dan nilai sipakatau mengharuskan seseorang memperlakukan orang lain sebagai manusia. Saling memanusiakan di sini memiliki makna menghormati harkat dan martabat kemanusian seseorang sebagai makhluk ciptaan Allah Subhanahu wa Ta'ala dan semua makhluk di sisi Allah adalah sama, yang membedakan adalah keimanan dan ketakwaan. Adapun data yang ditemukan berdasarkan hal tersebut yaitu:

"Bagaimana menurutmu, Pagala?

"Puang, ade' temmakeana' nennia temmakeappo"

"Nenek Mallomo sebagai hakim yang bijak lagi adil kemudian menjatuhkan vonis mati kepada putra tercintanya" (SRLCS, 87)

Berdasarkan data tersebut, sebagai hakim yang bijak dan adil tentunya harus melaksanakan segala bentuk aturan yang ada. Pagala atau yang biasa dikenal nenek Mallomo juga melaksanakan segala bentuk aturan yang sudah ditetapkan oleh sang raja, ketika seorang melakukan perbuatan mencuri tentunya akan dihukum sesuai dengan hukum yang ada pada waktu itu yaitu dengan hukuman mati walaupun yang melakukan pencurian tersebut merupakan cucu tercinta dari hakim yang bijak itu. Bahkan dengan tegasnya Pagala mengatakan 'Puang ade' temmakeana' nennia temmakeappo.

\section{b) Sipakalebbi}

Sipakalebbi yakni saling menghargai, biasanya terjadi secara horizontal bukan hanya terjadi dalam kalangan tertentu saja, misalnya kalangan bangsawan, dalam kalangan pejabat (dalam berbahasa) penggunaan kata ganti, mereka tidak menggunakan kata yang bermakna peyoratif (kamu) tetapi menggunakan sapaan yang baik, seperti idiq, puang, anri/andi, dan sebagainya sebagai petanda menghargai seseorang. Adapun data yang berkaitan dengan hal tersebut yaitu" 
Data 01

"La Pagala, apa yang terjdi dengan negeri ini ? Sepanjang sejarah, baru kali ini, negeri ini dilanda kemarau berkepanjangan."ungkap Raja La Patiroi saat nenek Mallomo daaing menghadap."

"Begini, Puang! Kemarau panjang ini diakibatkan oleh salah seorang rakyat bahkan penghuni sao raja ini tidak jujur”, tegas nenek Mallomo setelah memberi hormat Data 02 pada sang Raja” (SRLCS, 86-87)

"Daeng, kamu sama halnya membiarkan saya mati jika tetap meneruskan keinginanmu untuk menikah denganku" (SRLCS, 155)

Berdasarkan data 01 dan data 02, orang Bugis membangun komunikasinya dengan tujuan untuk saling menghargai dan mengapresiasi kedudukan masing-masing dalam masyarakat. Penggunaan sapaan "Puang dan Daeng" dalam tutur kata orang Bugis merupakan bentuk penghargaan. Dalam tradisi Bugis, "Puang dan Daeng" merupakan panggilan atau sapaan bagi orang dari golongan nigrat Bugis.

\section{c) Sipakainge}

Sipakainge artinya saling mengingatkan atau menasehati, yakni suatu hubungan interaksi dimana sifat pesan yang disampaikan mengandung peringatan positif, kebaikan serta nasehat. Adapun data yang berkaitan dengan hal tersebut yaitu :

"Anak-anakku, saya mengajak kalian untuk membaca fenomena alam ini sebagai azab Allah. Ingat, jangan menyalahkan siapa-siapa! Mari kita intropeksi diri, siapa tahu kemarau panjang ini karena ulah salah seorang di antara kita, temasuk saya" (SRLCS, 141)

Berdasarkan data tersebut, setiap manusia tidak akan terlepas dari kesalahan yang disengaja maupun tidak sengaja. Karena itu, selain sikap toleransi, sikap kritis pun harus dibangun sebagai upaya kontrol saling mengingatkan demi kepentingan bersama. Hal tersebut ditunjukkan oleh seorang guru yang mengingatkan kepada muridnya terkait fenomena alam yang terjadi sebagai azab Allah untuk tidak menyalahkan orang lain karena mungkin saja azab kemarau panjang tersebut merupakan kesalahan-kesalah yang dibuat oleh diri kita sendiri tanpa disadari.

\section{2) Kontribusi Analisis Novel terhadap Pendidikan Karakter di Sekolah}

Pendidikan karkater dilakukan melalui pendidikan nilai-nilai atau kebajikan yang menjadi dasar budaya dan karakter bangsa. Kebajikan yang menjadi atribut suatu karakter pada dasarnya adalah nilai. Oleh karena itu, pendidikan karakter pada dasarnya adalah pengembangan nilai-nilai yang berasal dari pandangan hidup atau ideologi bangsa Indonesia, agama, budaya, dan nilai-nilai yang terumuskan dalam tujuan pendidikan nasional (Mulyasa, 2011).

Pendidikan karakter merupakan salah satu upaya untuk menjawab berbagai tantangan kemanusiaan yang ditimbulkan oleh perkembangan teknologi yang begitu masif tersebut sehingga menusia atau siswa mampu menyikapi perkembangan teknologi secara tepat. Melalui proses pembalajaran yang dikemas dengan baik, termasuk penyusunan alat evaluasi, diharapkan dapat menjadikan siswa menjadi pribadi yang unggul, baik dari segi kognitif, afaktetif, maupun prikomotorik (Safi'i, 2008)..

Hasil penelitian ini yaitu berkaitan dengan masalah etika Bugis yang kemudian menemukan beberapa contoh-contoh etika Bugis dalam novel Sajak Rindu Lontara Cinta dari Sidenreng dan Sayat-sayat Sunyi karya S. Gegge Mappangewa yaitu sipakatau, sipakalebbi, dan sipakainge. Hasil penelitian ini di kontribusikan ke dalam pendidikan 
karakter di sekolah dengan cara setiap temuan akan diintegrasikan ke dalam semua mata pelajaran, pengembangan diri, dan pengembangan budaya sekolah sehingga mendapatkan sikap yang sesuai dengan aspek-aspek pendidikan karakter yaitu religious, jujur, disiplin, kerja keras, kreatif, mandiri, demokratis, rasa ingin tahu, semangat kebangsaan, cinta tanah air, menghargai prestasi, peduli lingkungan, dan peduli sosial. Menurut Pusat Kurikulum Kementrian Pendidikan Nasional sikap adalah aspek penilian yang teramat penting (nilai aspek 60\%). Sehingga guru dijadikan sebagai model ataupun teladan dalam sebuah pembentukan karakter pada peserta didik disekolah.

\section{Kesimpulan}

Berdasarkan hasil penelitian ini, dapat disimpulkan sebagai berikut; (1) Sipakatau yang ditemukan dalam novel Sajak Rindu Lontara Cinta dari Sidenreng yaitu, sikap hormat terhadap atasan, sikap hormat terhadap guru, sikap hormat terhadap aturan adat-istiadat yang berlaku, sikap hormat terhadap adab ataupun aturan makan dalam masyarakat Bugis, dan sikap hormat terhadap orang tua. (2) Sipakalebbi yang ditemukan dalam novel Sajak Rindu Lontara Cinta dari Sidenreng yaitu, saling menghargai kedudukan dilakukan dalam bentuk penggunaan sapaan, menghargai guru dalam bentuk senyuman, saling menghargai dalam kehidupan bertetangga, dan saling menghargai ketika bertamu. (3) Sipakainge yang ditemukan dalam novel Sajak Rindu Lontara Cinta dari Sidenreng yaitu, saling mengingatkan dan memberikan nasehat yang mengarah kepada kebaikan. (4) Hasil analisis novel Sajak Rindu Lontara Cinta dari Sidenreng kemudian dikontribusikan terhadap pendidikan karakter di sekolah sebagai langkah awal untuk membentuk karakter peserta didik yang baik dengan mempertimbangkan aspek moralitas, aspek religius, dan aspek psikologi.

\section{Saran}

Berdasarkan hasil penelitian yang diperoleh, maka penulis menyarankan beberapa hal sebagai berikut.

1) Bagi guru bahasa Indonesia, diharapkan dapat menjadi bahan acuan dalam pengembangan dan penerapan pengajaran sastra terkhusus novel.

2) Hasil penelitian ini secara umum menganalisis dengan kajian antropologi sastra dengan menggunakan teori-teori kearifan lokal berdasarkan objeknya. Diharapkan peneliti selanjutnya agar meneliti bagian yang lain dari teori-teori kearifan lokal.

\section{Daftar Pustaka}

Al-Ma'ruf, A. I., \& Nugraha, F. (2017). Pengkajian Sastra Teori dan Aplikasi. Katalog dalam Terbitan.

Aminuddin. (2011). Pengantar Apresiasi Sastra. Sinar Baru.

Ayuningtyas, Dian. 2015. Nilai Budaya Pada Novel Gugur Bunga Kedaton Karya Wahyu H.R: Kajian Antropologi Sastra dan Implementasinya dalam Pembelajaran Sastra di SMA. Program Studi Magister Pengkajian Bahasa Sekolah Pascasarjana. Universitas Muhammadiyah Surakarta.

Endraswara, Suwardi. (2013). Metodologi Penelitian Antropologi Sastra. Yogyakarta: Penerbit Ombek.

Fatimah, A., Syamsudduha, S., \& Usman, U. (2021). Analisis Wacana Kritis Novel Genduk Duku Karya Y.B Mangunwijaya dan Relevansinya dengan Pembelajaran Literasi Sastra berbasis Gender di SMA. Jurnal Kependidikan: Jurnal Hasil Penelitian dan Kajian Kepustakaan di Bidang Pendidikan, Pengajaran dan Pembelajaran, 7(2), 453462. doi:https://doi.org/10.33394/jk.v7i2.3741 
Fatmawati, F. (2013). Penerapan Adat Istiadat Suku Bugis sebagai Pembentuk Etika pada Anak Usia dini di Desa Latteko Kecamatan Awangpone Kabupaten Bone (Docotal Dissertation) Universitas Islam Negeri Alauddin Makassar.

https://news.detik.com/berita/d-4807940/kasus-bu-guru-tempeleng-siswi-smp-di-bulukumbagara-gara-hp-berujung-damai

Huzain, M. (2016). Sipakatau: Konsep Etika Masyarakat Bugis. Deepublish.

Khuta Ratna, N. (2011). Antropologi Sastra. Pustaka Pelajar.

Marsono. (2007). Revitalisasi Kearifan Lokal guna Mewujudkan Masyarakat Sejahtera dalam Kemajuan Terkini Riset UGM. Yogyakarta: LPPM UGM.

Miles, M. B. \& A., \& Hubermen, M. (2009). Analisis Data Kualitatif: Buku Sumber Tentang Metode-metode Baru (diterjemahkan Tjejep Rohendi Rohidi). UI Press.

Moien, M, G. Andi. (1990). Menggali Nilai-nilai Budaya-Makassar dan Siri na Pacce. Ujung Pandang: Yayasan "MAPRESS".

Moleong, J, L. (2006). Metodologi Penelitian Kualitatif. PT Remaja Rosdakarya.

Nadir. (2014). Urgensi Pembelajaran Berbasis Kearifan Lokal. Jurnal Pendidikan Agama Islam, 2(2), 301-330.

Nurgiyantoro, Burhan. (2015). (Cet: XI). Teori Pengkajian Fiksi. Yogyakarta: Gadja Mada University Press.

Permendikbud. (2013). Tentang Permendiknas Nomor 22/2006 Tentang Standar Isi untuk Satuan Pendidikan Dasar dan Menengah. Jakarta: Depdiknas 2013.

Pradopo, Rahmat Djoko. (2003). Prinsip-prinsip Kritik Sastra. Yogyakarta: Gadja Mada University Press.

Ridwan, N. A. (2007). Landasan Keilmuan Kearifan Lokal. Jurnal Studi Islam dan Budaya. IAIN Purwokerto, 5(1), 27-38.

Riski Dianita, Nindya. 2018. Sikap Hidup Sirri' Na Pesse Masyarakat Bugis Dalam Novel Calabai Perempuan Dalam Tubuh Lelaki karya Peppi Al-Bayqunie. Pendidikan Bahasa dan Sastra Indonesia, Fakultas Bahasa dan Seni. Universitas Negeri Surabaya.

Rustan, A. S. (2008). Pola Komunikasi Orang Bugis (Kompromi antara Islam dan Budaya). Pustaka Pelajar.

Safi'i, Imam. (2008). Nilai-nilai Pendidikan Karakter dalam Alat Evaluasi Bahasa Indonesia. Universitas Muhammadiyah Prof. Dr. HAMKA Jakarta.

Safriadi. (2020). Falsafah Hidup Bugis Terhadap Budaya Kerja Pada PT Amanah di Makassar. Universitas Hasanuddin. Makassar

Sagala, S. (2013). Etika dan Moralitas pendidikan. KENCANA.

Sari, Dina, Purnama. (2015). Travel Writing sebagai Inovasi Pendidikan pada Novel Etnografi Manusia Langit Karya J. A. Sanjaya. Akademi Bahasa Asing Bina Sarana Informatika. Jakarta.

Staton, R. (2012). Teori Fiksi. Yogyakarta: Pustaka Pelajar.

Syarif, N., Tang, M., \& Usman, U. (2021). Idealisasi Nilai Pendidikan Lingkungan dalam Novel Anak Rantau (Kajian Ekokritik). Jurnal Kependidikan: Jurnal Hasil Penelitian dan Kajian Kepustakaan di Bidang Pendidikan, Pengajaran dan Pembelajaran, 7(2), 306-313. doi:https://doi.org/10.33394/jk.v7i2.3735

Teeuw. (2015). Sastra dan Ilmu Sastra: Pengantar Teori Sastra. Jakarta: Pustaka Jaya.

Warigan. (2012). Pengembangan Karakter Berbasis Kearifan Lokal Hamemayu Hayuning Bawana (Identifikasi Nilai-nilai Karakter Berbasis Budaya. Yogyakarta: Universitas Negeri Yogyakarta.

Zulhan, Najib. (2011). Pendidikan Berbasis Pendidikan Karakter: JePe Press Media Utama. 